\title{
How expensive is a cardioprotective diet? Analysis from the CRESSIDA study
}

\author{
Dianne P Reidlinger ${ }^{1,2, *}$, Thomas AB Sanders ${ }^{2}$ and Louise M Goff ${ }^{2}$ \\ ${ }^{1}$ Faculty of Health Sciences and Medicine, Bond University, 2 Promethean Way, Robina, QLD 4226, Australia: \\ ${ }^{2}$ Faculty of Life Sciences \& Medicine, Diabetes and Nutritional Sciences Division, King's College London, London, UK
}

Submitted 11 July 2016: Final revision received 13 November 2016: Accepted 5 December 2016: First published online 18 January 2017

\begin{abstract}
Objective: To determine whether a cardioprotective dietary intervention based on UK dietary guidelines was more expensive than a conventional UK diet.

Design: Cost analysis of food records collected at baseline and after a 12-week dietary intervention of a cardioprotective diet $v$. conventional UK diet.

Setting: A randomized controlled dietary intervention study (CRESSIDA; ISRCTN 92382106) investigating the impact of following a diet consistent with UK dietary guidelines on CVD risk.

Subjects: Participants were healthy UK residents aged 40-70 years. A sub-sample of participants was randomly selected from those who completed the cardioprotective dietary intervention ( $n$ 20) or the conventional UK dietary intervention ( $n$ 20).

Results: Baseline diet costs did not differ between groups; mean daily food cost for all participants was £6.12 (SD £1.83). The intervention diets were not more expensive: at end point the mean daily cost of the cardioprotective diet was $£ 6.43$ (SD £2.05) $v$. the control diet which was £6.53 (SD £1.53; $P=0 \cdot 86$ ).

Conclusions: There was no evidence that consumption of a cardioprotective diet was more expensive than a conventional dietary pattern. Despite the perception that healthier foods are less affordable, these results suggest that cost may not be a barrier when modifying habitual intake and under tightly controlled trial conditions. The identification of specific food groups that may be a cost concern for individuals may be useful for tailoring interventions for CVD prevention for individuals and populations.
\end{abstract}

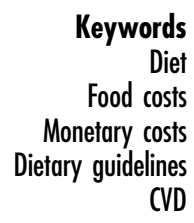

The promotion of healthy dietary patterns that help to protect individuals and populations from developing chronic diseases such as hypertension and CVD is a public health priority. The question of whether healthier diets are more expensive than less health-promoting eating patterns remains contentious. Cross-sectional studies across a number of countries have modelled the cost of healthier dietary patterns and consistently found them to be more expensive $^{(1-6)}$. Specifically in the UK, analysis from the Women's Cohort Study found that the amount of money spent was predictive of healthier eating ${ }^{(7)}$ and healthier dietary patterns were found to cost twice as much as less healthy dietary patterns ${ }^{(8)}$. Further, data from the UK National Diet and Nutrition Survey (NDNS) showed energy intake to be strongly correlated with dietary cost and lower food costs for some subgroups of the population including people in low-income categories and those who consumed less than recommended quantities of fruit and vegetables ${ }^{(9)}$. Pooling data from the published studies, a meta-analysis was recently published which concluded that healthier foods and dietary patterns are more expensive than less healthy foods and patterns ${ }^{(10)}$.

Despite this finding across multiple studies and countries, intervention studies that cost changes in actual food intake do not consistently show higher costs associated with higher-quality diets. A number of studies, including an analysis from the Finnish Diabetes Prevention Study ${ }^{(11)}$ demonstrated no change in $\operatorname{costs}^{(12,13)}$, while some have shown decreased ${ }^{(14)}$ or increased spending ${ }^{(15)}$ when dietary quality is improved. However, there has been no costing of UK intervention studies published to date. There is a need to assess the financial impact of changing habitual food intake to reflect a healthier dietary pattern in a UK context. The present study aimed to determine if a cardioprotective dietary intervention based on UK dietary guidelines was more expensive than a conventional UK diet; and to explore the change in food group costs when altering habitual intake. 


\section{Methods}

\section{Study design and participants}

The study design was a retrospective analysis of food records completed by participants who completed CRESSIDA (Cardiovascular Disease risk REduction Study; http://www.isrctn.com ISRCTN no. 92382106), a 12-week dietary intervention study. A description of the original study methods and results has been published elsewhere $^{(16)}$. Briefly, 162 healthy participants aged $40-70$ years were randomized to either a cardioprotective diet ( $n$ 80; based on current UK dietary guidelines ${ }^{(17)}$ : salt restricted to less than $6 \mathrm{~g} / \mathrm{d}$, SFA less than $10 \%$ of energy, increased whole grains to greater than $50 \%$ of cereal intake, five portions fruit and vegetables per day and increased fish intake to two portions per week, one of which should be oily) or a control diet ( $n$ 82) reflecting a dietary pattern representative of one eaten by many people in this age group in the $\mathrm{UK}^{(18)}$ (nutritionally balanced diet containing mostly refined cereals, meat (meat products, poultry, nonoily fish), full-fat dairy products, potatoes and at least one portion of fruit and two portions of vegetables per day). Individualized dietary advice was provided by a research dietitian to each participant. However, specific advice was not provided on how to shop cost effectively for the interventions allocated; instead the focus of advice was on aherence to the dietary intervention that the participant was allocated.

For the current study, a feasible sample of forty participants ( $n 20$ from each arm) from the total CRESSIDA sample (n 162) was randomly selected using a computerized random number generator. Equal numbers of male and female participants, and of those allocated to the intervention and control groups, were included in the sample.

\section{Development of a food cost database}

Each participant completed a $4 \mathrm{~d}$ estimated food diary at baseline and after 12 weeks. A food cost database was constructed by compiling a full list of food codes from the sample, de-duplicating repeat codes and decoupling codes that incorporated more than one ingredient (e.g. potatoes mashed with butter was separated into the code for potatoes and a code for butter, and a formula to include $50 \mathrm{~g}$ of butter per $1 \mathrm{~kg}$ of potatoes purchased was applied to the original code for costing purposes). Where ingredients as purchased required home processing, the edible portion of the whole food was used as a multiplication factor of the food weight.

Food prices were obtained from two online supermarkets (one identified as 'budget' and the other a mid-priced 'regular' supermarket) between January and March 2013 for all foods recorded. Prices were also obtained from two additional online supermarkets for all foods recorded by a smaller number of participants ( $n$ 12; distributed equally across both groups) to obtain a multiplication factor for another 'regular' supermarket as well as a higher priced 'quality' supermarket. Foods were priced using own brand products where available or the brand available at the majority of the four supermarkets. The cost of the food was based on medium sized packages and where possible comparable package sizes were priced across supermarkets. The cost per gram of the food was obtained by dividing the purchase price by the edible portion weight of the food. Sale or multi-buy prices were disregarded and the usual selling price of the food item was used for the database. Several food items were provided to participants in both arms, as part of the dietary intervention to aid compliance ${ }^{(16)}$; for these foods, prices were obtained for the actual brand and package size provided.

\section{Calculation of dietary cost}

A list of foods and portion weights was generated from the diaries. For each participant at each time point, edible portion food costs were calculated by multiplying the weight of each food item by the unit cost in the food cost database (in £ sterling). Total costs of all foods and beverages consumed over the four days were then averaged to derive a mean daily cost. Foods were categorized into food groups according to the categorization used in the UK food composition tables ${ }^{(19)}$ to assess changes in the weight and cost of each food group during the intervention. The cost of home-cooked dishes was obtained by using the recipe provided by the participant; if no recipe was provided a standard recipe was sourced from the UK food tables ${ }^{(19)}$, a UK food industry recipe book ${ }^{(20)}$ or the BBC Good Food website $^{(21)}$. Costing of recipes, as for individual food items, was based on the edible portion of the food.

\section{Statistical analysis}

All statistical analyses were performed using the statistical software package IBM SPSS Statistics Version 20.0. Distributional checks for normality were undertaken using Q-Q plots. Paired $t$ tests were used to compare mean baseline and end-point costs within each group. Independent-samples $t$ tests were calculated to assess differences between groups for mean change in costs from baseline to end point, mean change in weight and daily cost by food group, and mean cost at end point by food group. The differences in amounts of foods and costs according to food group categories between the groups at end point were analysed using ANCOVA, with baseline cost as a covariate. Mean difference was presented as the difference between cardioprotective group costs and control group costs.

\section{Results}

\section{Baseline characteristics}

Food and beverage intakes from $4 \mathrm{~d}$ food diaries were costed for forty participants (cardioprotective $n$ 20, control $n$ 20) 
of the CRESSIDA randomized controlled trial at baseline and post-intervention (12 weeks later). The baseline characteristics of the participants are shown in Table 1 and compared with those of all participants completing the CRESSIDA ( $n$ 162); the costed sample was comparable to the whole cohort apart from $\mathrm{Na}$ intake, which was higher in the costed sample.

\section{Change in diet cost during intervention}

At baseline, the mean daily food cost for all participants was $£ 6 \cdot 12$ (SD £1.83), ranging from £5.22 (SD £1.57) in the budget supermarket to $£ 7 \cdot 78$ (SD $£ 2.43$ ) in the quality supermarket. There was no difference in diet cost between the cardioprotective and control groups for any supermarket. Following the intervention, there was no significant change in diet cost between groups (Table 2).

Baseline dietary intake categorized into food groups indicated higher costs $(P<0.005)$ at baseline in the cardioprotective group for dairy $(£ 0 \cdot 22 / \mathrm{d})$ and fruit $(£ 0 \cdot 41 / \mathrm{d})$, reflecting higher intakes, and possibly higher-cost choices for these foods, at the start of the intervention. However, the change from baseline in consumption of foods (by weight) in each food group was not different between groups (Table 3).
There was a significant difference in costs at end point between groups for dairy and non-alcoholic drinks, which were higher for the control group, and fish, sugar and snack foods, which were higher for the cardioprotective group. The difference in costs was due to the foods chosen within the food groups, rather than a change in the amount of foods consumed within food groups. For example, for the dairy group, the mean difference at end point (after accounting for baseline intakes) was $30 \mathrm{~g} / \mathrm{d}$ with the cardioprotective group consuming about two dessertspoons more dairy at end point ( $P=0.66)$ compared with the control group, but spending $£ 0.33$ less per day $(P=0.012)$. Similarly, mean fish intake at end point was about $10 \mathrm{~g} / \mathrm{d}$ less in the cardioprotective group compared with the control group $(P=0 \cdot 67)$, but the mean daily spend on fish was $£ 0.58$ more ( $P=0.038$; Table 3 ).

The ranking of food groups by cost at end point demonstrated similar rankings for four of the top five most expensive food groups across both intervention arms. The exceptions were the fish food group (included in the top five for cost for the cardioprotective group but not the control group) and alcohol food group (included in the top five food groups for cost in the control diet group but not for the cardioprotective group; Table 4).

Table 1 Baseline characteristics of participants in the costed sample and all participants who completed the CRESSIDA study

\begin{tabular}{|c|c|c|c|c|c|}
\hline \multirow[b]{2}{*}{ Characteristic } & \multicolumn{2}{|c|}{ Costed sample ( $n$ 40) } & \multicolumn{2}{|c|}{ All CRESSIDA ( $n$ 162) } & \multirow[b]{2}{*}{$P$ value } \\
\hline & Mean & SD & Mean & SD & \\
\hline Age (years) & $52 \cdot 0$ & 8.5 & $52 \cdot 6$ & $8 \cdot 0$ & 0.68 \\
\hline Gender $(\mathrm{M} / \mathrm{F}, n)$ & \multicolumn{2}{|c|}{$20 / 20$} & \multicolumn{2}{|c|}{$65 / 99$} & \\
\hline BMI $\left(\mathrm{kg} / \mathrm{m}^{2}\right)$ & $25 \cdot 1$ & 3.6 & $26 \cdot 1$ & 3.9 & 0.14 \\
\hline $\mathrm{SBP}(\mathrm{mmHg})$ & 118.4 & $16 \cdot 3$ & 119.9 & $16 \cdot 0$ & 0.58 \\
\hline DBP $(\mathrm{mmHg})$ & 76.9 & 7.9 & 78.7 & 9.6 & 0.27 \\
\hline Energy $(\mathrm{kJ} / \mathrm{d}) \dagger$ & 9738 & 2708 & 8914 & 2362 & 0.06 \\
\hline Energy $(\mathrm{kcal} / \mathrm{d}) \dagger$ & 2327.5 & 647.3 & $2130 \cdot 4$ & 564.6 & 0.06 \\
\hline Protein (g/4184kJ) & $40 \cdot 7$ & 8.1 & 39.8 & 7.6 & 0.51 \\
\hline Carbohydrate (g/4184 kJ) & $119 \cdot 7$ & $17 \cdot 1$ & $119 \cdot 7$ & $18 \cdot 8$ & 0.99 \\
\hline Fat $(\mathrm{g} / 4184 \mathrm{~kJ})$ & $39 \cdot 8$ & 7.7 & $39 \cdot 3$ & 6.8 & 0.71 \\
\hline Saturated fat (g/4184 kJ) & $13 \cdot 3$ & $4 \cdot 1$ & $13 \cdot 2$ & 3.7 & 0.94 \\
\hline Fibre (g/4184 kJ) & $10 \cdot 8$ & 3.6 & 11.4 & 3.7 & 0.35 \\
\hline $\mathrm{Na}(\mathrm{mg} / 4184 \mathrm{~kJ})$ & $1704 \cdot 2$ & 481.9 & 1493.4 & 395.9 & 0.004 \\
\hline Sugar (g/4184 kJ) & 51.3 & $16 \cdot 4$ & 51.8 & $14 \cdot 6$ & 0.83 \\
\hline
\end{tabular}

M, male; F, female; SBP, systolic blood pressure; DBP, diastolic blood pressure.

${ }^{*} P$ value for between-group difference at baseline using the independent-samples $t$ test; significant $P$ values are shown in bold.

†Energy between groups is approaching significance, likely due to the higher proportion of males in the costed sample (50\%) compared with the overall CRESSIDA sample (about $33 \%$ male). Therefore the remaining nutrient data are presented as grams (or milligrams) per $4184 \mathrm{~kJ}$ (1000 kcal).

Table 2 Daily cost and mean difference in cost of diet for cardioprotective and control groups by supermarket; CRESSIDA study

\begin{tabular}{|c|c|c|c|c|c|c|c|c|c|c|c|}
\hline \multirow[b]{3}{*}{ Supermarket } & \multicolumn{4}{|c|}{ Cardioprotective $(n 20)(£ / d)$} & \multicolumn{4}{|c|}{ Control $(n 20)(£ / d)$} & \multirow[b]{3}{*}{ Mean difference $(£ / d)$} & \multirow[b]{3}{*}{$95 \% \mathrm{Cl}$} & \multirow[b]{3}{*}{$P$ value } \\
\hline & \multicolumn{2}{|c|}{ Baseline } & \multicolumn{2}{|c|}{ End point } & \multicolumn{2}{|c|}{ Baseline } & \multicolumn{2}{|c|}{ End point } & & & \\
\hline & Mean & SD & Mean & SD & Mean & SD & Mean & SD & & & \\
\hline Budget & $5 \cdot 26$ & 1.70 & 5.58 & 1.80 & $5 \cdot 22$ & 1.57 & 5.50 & $1 \cdot 35$ & 0.09 & $-0.93,1.10$ & 0.86 \\
\hline Regular 1 & 6.01 & 1.94 & $6 \cdot 21$ & 1.95 & 5.92 & 1.67 & 6.54 & 1.50 & -0.33 & $-1.45,0.78$ & 0.55 \\
\hline Regular $2 \dagger$ & $5 \cdot 72$ & 1.87 & 5.97 & 1.90 & 5.66 & 1.56 & 6.08 & 1.41 & -0.11 & $-1.18,0.96$ & 0.84 \\
\hline Quality $\dagger$ & $7 \cdot 78$ & 2.43 & 7.94 & 2.57 & 7.41 & $2 \cdot 13$ & 8.00 & 1.98 & -0.06 & $-1.53,1.40$ & 0.93 \\
\hline Mean all & $6 \cdot 19$ & 1.97 & $6 \cdot 43$ & $2 \cdot 05$ & 6.05 & $1 \cdot 72$ & 6.53 & 1.53 & -0.11 & $-1 \cdot 26,1.05$ & 0.86 \\
\hline
\end{tabular}

${ }^{\star} P$ value for between-group difference at end point using the independent-samples $t$ test.

†Factored costs. 
Table 3 Baseline, end point and mean difference in daily amount and cost of food groups for participants in the cardioprotective and control diet; CRESSIDA study

\begin{tabular}{|c|c|c|c|c|c|c|c|c|c|c|c|}
\hline \multirow[b]{3}{*}{ Food group } & \multicolumn{4}{|c|}{ Cardioprotective (n 20) } & \multicolumn{4}{|c|}{ Control (n 20) } & \multirow[b]{3}{*}{ Mean difference* } & \multirow[b]{3}{*}{$95 \% \mathrm{Cl}$} & \multirow[b]{3}{*}{$P$ value } \\
\hline & \multicolumn{2}{|c|}{ Baseline } & \multicolumn{2}{|c|}{ End point } & \multicolumn{2}{|c|}{ Baseline } & \multicolumn{2}{|c|}{ End point } & & & \\
\hline & Mean & SD & Mean & SD & Mean & SD & Mean & SD & & & \\
\hline \multicolumn{12}{|c|}{ Cereals and grains } \\
\hline $\mathrm{g} / \mathrm{d}$ & $286 \cdot 2$ & $137 \cdot 0$ & $300 \cdot 9$ & $136 \cdot 2$ & $346 \cdot 4$ & $150 \cdot 9$ & $282 \cdot 1$ & $136 \cdot 1$ & $-9 \cdot 7$ & $-105 \cdot 0,85 \cdot 5$ & 0.84 \\
\hline$£ / d$ & 0.77 & 0.48 & 0.91 & 0.59 & 0.93 & 0.47 & 0.70 & 0.32 & 0.21 & $-0.25,0.67$ & 0.36 \\
\hline \multicolumn{12}{|l|}{ Dairy } \\
\hline $\mathrm{g} / \mathrm{d}$ & 386.4 & 143.5 & 355.7 & $221 \cdot 1$ & $250 \cdot 0$ & $119 \cdot 1$ & 274.0 & $158 \cdot 1$ & $30 \cdot 3$ & $-111 \cdot 4,172 \cdot 1$ & 0.66 \\
\hline$£ / d$ & $0.65 \ddagger$ & 0.32 & 0.38 & 0.28 & $0.43 \ddagger$ & 0.23 & 0.53 & 0.32 & -0.33 & $-0.59,-0.08$ & 0.012 \\
\hline \multicolumn{12}{|l|}{ Eggs } \\
\hline $\mathrm{g} / \mathrm{d}$ & $15 \cdot 1$ & $21 \cdot 7$ & 9.9 & $14 \cdot 8$ & $17 \cdot 3$ & $20 \cdot 3$ & $24 \cdot 6$ & $22 \cdot 1$ & $12 \cdot 5$ & $-2 \cdot 5,27.5$ & 0.10 \\
\hline$£ / d$ & 0.05 & 0.08 & 0.04 & 0.05 & 0.08 & 0.09 & 0.11 & 0.10 & -0.01 & $-0.07,0.05$ & 0.65 \\
\hline \multicolumn{12}{|l|}{ Vegetables } \\
\hline $\mathrm{g} / \mathrm{d}$ & 374.6 & $182 \cdot 8$ & $446 \cdot 4$ & $279 \cdot 3$ & 333.9 & $158 \cdot 0$ & $333 \cdot 8$ & $124 \cdot 2$ & $-146 \cdot 0$ & $-297 \cdot 9,5 \cdot 8$ & 0.06 \\
\hline$£ / d$ & 1.01 & 0.58 & 0.99 & 0.61 & 0.88 & 0.56 & 0.89 & 0.40 & 0.21 & $-0.19,0.60$ & 0.29 \\
\hline \multicolumn{12}{|l|}{ Fruit } \\
\hline$g / d$ & $281 \cdot 0$ & $175 \cdot 7$ & 298.8 & $180 \cdot 1$ & $211 \cdot 2$ & 221.5 & $209 \cdot 0$ & $167 \cdot 8$ & $-60 \cdot 2$ & $-174 \cdot 7,54.3$ & 0.29 \\
\hline$£ / d$ & $0.84 \ddagger$ & 0.68 & 0.81 & 0.68 & $0.43 \ddagger$ & 0.42 & 0.56 & 0.48 & -0.07 & $-0.59,0.45$ & 0.80 \\
\hline \multicolumn{12}{|l|}{ Nuts } \\
\hline$g / d$ & 8.5 & $18 \cdot 1$ & 8.8 & $10 \cdot 2$ & 21.5 & $46 \cdot 3$ & $17 \cdot 0$ & $25 \cdot 1$ & $2 \cdot 7$ & $-11 \cdot 4,16 \cdot 8$ & 0.70 \\
\hline$£ / d$ & 0.06 & 0.12 & 0.10 & 0.13 & 0.17 & 0.38 & 0.12 & $0 \cdot 18$ & 0.07 & $-0.05,0.20$ & 0.22 \\
\hline \multicolumn{12}{|l|}{ Fish } \\
\hline$g / d$ & $49 \cdot 1$ & $43 \cdot 2$ & $82 \cdot 2$ & $61 \cdot 0$ & $60 \cdot 3$ & $60 \cdot 8$ & $48 \cdot 1$ & $44 \cdot 8$ & -9.9 & $-56 \cdot 7,37 \cdot 0$ & 0.67 \\
\hline$£ / d$ & 0.50 & 0.47 & 0.99 & 0.84 & 0.48 & 0.44 & 0.36 & 0.25 & 0.58 & $0.03,1.13$ & 0.038 \\
\hline \multicolumn{12}{|l|}{ Meat } \\
\hline$g / d$ & $156 \cdot 4$ & 111.5 & 111.8 & 94.5 & $198 \cdot 9$ & $113 \cdot 1$ & $158 \cdot 3$ & $112 \cdot 4$ & $22 \cdot 7$ & $-50 \cdot 7,96 \cdot 0$ & 0.53 \\
\hline$£ / d$ & 1.13 & 1.03 & 1.02 & 1.02 & 1.44 & 0.95 & 1.40 & 1.06 & -0.06 & $-0.83,0.71$ & 0.87 \\
\hline \multicolumn{12}{|l|}{ Fats and oils } \\
\hline$g / d$ & $19 \cdot 4$ & $13 \cdot 6$ & $21 \cdot 4$ & 11.6 & $15 \cdot 1$ & $12 \cdot 3$ & $18 \cdot 2$ & $13 \cdot 8$ & $-4 \cdot 2$ & $-14 \cdot 3,5 \cdot 8$ & 0.40 \\
\hline$£ / d$ & 0.08 & 0.06 & 0.08 & 0.05 & 0.06 & 0.05 & 0.08 & 0.07 & -0.02 & $-0.07,0.03$ & 0.39 \\
\hline \multicolumn{12}{|c|}{ Non-alcoholic drinks } \\
\hline$g / d$ & $929 \cdot 3$ & $378 \cdot 4$ & $1002 \cdot 5$ & 533.1 & 841.9 & 550.5 & $913 \cdot 4$ & $642 \cdot 8$ & $-34 \cdot 2$ & $-294 \cdot 9,226 \cdot 4$ & 0.79 \\
\hline$£ / d$ & 0.30 & 0.25 & 0.20 & 0.15 & 0.39 & 0.41 & 0.46 & 0.49 & -0.37 & $-0.61,-0.14$ & 0.003 \\
\hline \multicolumn{12}{|c|}{ Alcoholic drinks } \\
\hline$g / d$ & $157 \cdot 8$ & $227 \cdot 7$ & $145 \cdot 3$ & $258 \cdot 2$ & $184 \cdot 2$ & 195.5 & 191.9 & $146 \cdot 4$ & $-1 \cdot 34$ & $-135 \cdot 8,133 \cdot 1$ & 0.98 \\
\hline$£ / d$ & 0.51 & 0.61 & 0.46 & 0.65 & 0.52 & 0.71 & 0.87 & 0.75 & -0.27 & $-0.75,0.20$ & 0.25 \\
\hline \multicolumn{12}{|c|}{ Sugar and snack foods } \\
\hline $\mathrm{g} / \mathrm{d}$ & $26 \cdot 7$ & 21.5 & 27.5 & $14 \cdot 8$ & 29.9 & 27.5 & 29.9 & $20 \cdot 5$ & $-6 \cdot 1$ & $-19 \cdot 1,7 \cdot 0$ & 0.35 \\
\hline$£ / d$ & 0.22 & 0.09 & 0.36 & 0.30 & 0.16 & 0.16 & 0.21 & 0.26 & 0.22 & $0.14,0.42$ & 0.037 \\
\hline
\end{tabular}


Table 4 Mean cost at end point by food group* for cardioprotective and control diet groups; CRESSIDA study

\begin{tabular}{|c|c|c|c|c|c|c|}
\hline \multirow[b]{3}{*}{ Food group } & \multicolumn{3}{|c|}{ Cardioprotective group } & \multicolumn{3}{|c|}{ Control group } \\
\hline & \multirow[b]{2}{*}{ Ranking } & \multicolumn{2}{|c|}{ Cost $(£ / 4 d)$} & \multirow[b]{2}{*}{ Ranking } & \multicolumn{2}{|c|}{ Cost $(£ / 4 d)$} \\
\hline & & Mean & SD & & Mean & SD \\
\hline Meat & 1 & 4.07 & 4.08 & 1 & 5.53 & 4.13 \\
\hline Fish & 2 & 3.95 & 3.36 & 8 & 1.36 & 1.04 \\
\hline Vegetables & 3 & 3.95 & 2.44 & 2 & 3.46 & 1.61 \\
\hline Cereals & 4 & $3 \cdot 62$ & $2 \cdot 35$ & 4 & $2 \cdot 82$ & $1 \cdot 24$ \\
\hline Fruit & 5 & 3.23 & $2 \cdot 70$ & 5 & $2 \cdot 17$ & 1.87 \\
\hline Alcoholic drinks & 6 & 1.82 & $2 \cdot 60$ & 3 & 3.29 & 3.02 \\
\hline Dairy & 7 & 1.53 & $1 \cdot 12$ & 6 & 2.06 & 1.27 \\
\hline Sugar and snack foods & 8 & 1.45 & 1.08 & 9 & 0.81 & 1.01 \\
\hline Non-alcoholic drinks & 9 & 0.80 & 0.60 & 7 & 1.85 & 1.97 \\
\hline Nuts & 10 & 0.41 & 0.52 & 10 & 0.47 & 0.72 \\
\hline Fats and oils & 11 & 0.31 & 0.18 & 12 & 0.38 & 0.32 \\
\hline Eggs & 12 & 0.15 & 0.22 & 11 & 0.41 & 0.38 \\
\hline
\end{tabular}

${ }^{\star}$ End-point costs for $4 \mathrm{~d}$ intake as recorded in estimated food diaries.

\section{Discussion}

The key finding of the present study is that a cardioprotective dietary pattern based on UK dietary guidelines was not more expensive than a control diet representative of the habitual intake of similarly aged people in the UK. While overall the cardioprotective diet was not more expensive we did find increased spending in certain food groups; however, total food expenditure did not change, suggesting that any increased costs were balanced by savings in other food groups. These results suggest that cost may not be a barrier to modifying habitual intake to reflect a more cardioprotective dietary pattern.

The finding of no overall difference in cost is in agreement with evidence from other intervention studies ${ }^{(11-14,22)}$; however, it contradicts the body of evidence from observational studies ${ }^{(8,23-26)}$ and a recent meta-analysis of cross-sectional studies, which concluded healthier dietary patterns to be more expensive than less healthy patterns ${ }^{(10)}$. Our study is the first analysis of an intervention study based on UK food prices, which differ from those of the rest of Europe; for example, food prices rose by $32 \%$ in the UK between 2007 and 2012, but by only $13 \%$ in the same time period in France and Germany ${ }^{(27)}$. Around the world different countries operate under unique market conditions, with international variation in price, taxation, balance of imports and exports, manufacturing and distribution costs affecting food costs. Thus comparisons are made more difficult when data are across countries and at different time points, notwithstanding the methodological rigour adopted by Rao et al. in standardizing to a commonyear US dollar ${ }^{(10)}$. There are a number of additional factors that may explain the conflicting evidence. The methods used to calculate food costs vary, including per energy unit (e.g. cost per $4184 \mathrm{~kJ} / 1000 \mathrm{kcal}$ ), by weight (e.g. cost per $100 \mathrm{~g}$ ) or - less frequently due to the practicalities in determining an average quantity - per portion (i.e. cost per single portion). Such methodological differences are the subject of much academic debate ${ }^{(28)}$. Whereas there is good evidence of an inverse relationship between dietary energy density and nutrient intakes ${ }^{(4,29,30)}$, the usefulness of pricing foods per energy unit when costing higher-quality diets has been questioned ${ }^{(10)}$. Foods lower in dietary energy for weight, such as fruit and vegetables, have a higher price when measured per energy unit ${ }^{(28)}$ rather than by weight; however, they are generally also of a higher nutrient density (in the form of vitamins, minerals and dietary fibre, for example) than foods that have higher energy for weight ${ }^{(31)}$. Furthermore, in cross-sectional studies food selection and cost may be more greatly impacted by additional influences on food purchasing behaviour such as nutrition and food knowledge and the ability to shop, which are likely be somewhat ameliorated in a dietary intervention study with individualized advice.

The results of the present study highlight the variable amounts spent proportionately on food groups with different dietary patterns, which is in agreement with previous work ${ }^{(10)}$. Although cost was different between the two dietary patterns for some food groups, actual consumption (by weight) did not change significantly for any food group, suggesting that individual food choices within the food groups were driving the cost differences. In the cardioprotective group, total daily costs were significantly higher for fish (due to the encouragement of regular oily fish intake as part of the intervention) and for sugar and snack foods (reflecting the provision of wholegrain cereal nut bars, a considerably more expensive choice than the biscuits and cakes they were intended to replace); but lower for non-alcoholic drinks and eggs. Given that biomarkers of intake in the original study ${ }^{(16)}$ supported compliance to increased whole grains and oily fish intakes, and reduced added sugars intake in the cardioprotective group, it is likely that the changes to costs reflected improvements in the quality of the diet (rather than quantity) for the cardioprotective diet group. Greater spending on wholegrain cereals has been noted with more 
health-promoting diets ${ }^{(3)}$ and in the current study there was a slightly greater (about $£ 0 \cdot 80 / d$ ), but not statistically significant, daily spend on cereals in the cardioprotective group. Similarly, the results support a trend for spending more on meat with less healthier diets ${ }^{(3)}$, but it did not reach statistical significance. Despite these differences in costs across food groups, there was little difference in actual rankings of food groups at end point, with the aggregated top five food groups by cost in both groups remarkably similar. Only one food group difference was evident in the top five: fish, which ranked second for participants in the cardioprotective group but only eighth in the control group; and alcohol, which ranked third in the control group and sixth in the cardioprotective diet group. There was no significant difference between groups in the amount and cost of alcohol consumed after 12 weeks of following the dietary advice; however, there was a significantly lower cost of non-alcoholic drinks for the cardioprotective group. Both groups were given the same advice about alcohol: that it could be consumed in moderation, with a recommendation of no more than 3 units of alcohol per day (and a maximum of 21 units in a week) for men and no more than 2 units of alcohol per day (maximum 14 units in a week) for women. Specific advice to avoid sugar-sweetened beverages was provided to the cardioprotective group; however, advice to the control group aligned with the EatWell plate which grouped these beverages (with advice provided to moderate intake) together with other discretionary foods such as cakes, biscuits and crisps.

The perception that healthier foods are less affordable is frequently cited as a barrier to improving dietary habits ${ }^{(32,33)}$; however, the current study suggests this is not the case when manipulating habitual intake under tightly controlled trial conditions and costing foods as consumed. Implementing similar dietary changes in priority groups (i.e. those on lower incomes with poorer health outcomes) could, however, be challenging for a number of reasons. People on lower incomes spend a greater proportion of their income on food overall ${ }^{(34)}$, making them more vulnerable to rising food costs, and there is evidence that those with less money to spend on food are more likely to purchase energy-dense foods with a higher proportion of refined grains, added sugars and fats as an economic strategy to save money ${ }^{(35)}$. While the cost of changing to foods that are more consistent with dietary guidelines may not be greater for people with more elastic food budgets, the same may not be the case for those with less flexibility. For those with families particularly, there is the inherent risk that purchasing different foods will be more expensive if the new food is not popular with children, resulting in more acceptable alternatives having to be purchased ${ }^{(36)}$ thus increasing overall household food costs. These barriers may be amenable to intervention through programmes directly targeting lower-income families; a recent evaluation of a sustained programme for disadvantaged families in Australia suggested that interventions focused on food budgeting skills may be promising. Key concepts on cost included in that programme were meal and food purchase planning based on the proportion of food budget to be spent on different food groups and price per kilogram principles for comparing individual food items $^{(37)}$. However, it is acknowledged that for many individuals, sociocultural barriers to the adoption of healthier food habits (such as family norms, financial insecurity, lack of choice in where food is purchased from) may be more important than food purchasing knowledge or skills per $s e^{(36,38)}$. Other factors may influence consumers' perceptions of the relative cost of food. For example, rather than just considering the cost of food at the point of sale, consumers may factor in other attributes they perceive as contributing to expense but not directly related to cost. These include the shelf-life of individual food items, potential for spoilage during transport and storage, and changes to the quality of different food items over time ${ }^{(32)}$. In this way, fresh fruit may be viewed by consumers as more 'expensive' than canned fruit as they may spoil during transport or storage, whereas the canned counterparts by contrast are perceived to retain their quality indefinitely.

A key strength of the present study is the robustness of the dietary data, taken from $4 \mathrm{~d}$ food diaries with detailed information about actual foods consumed, which is not possible to obtain from FFQ. The dietary data correlated well with objective biomarkers of dietary intake ${ }^{(16)}$ and the food price data reflect the cost of diets as actually consumed by the individual participants. The baseline food expenditure (equivalent to $£ 42.84$ per week) was comparable to estimates of household expenditure on foods and non-alcoholic drinks in England (a mean of $£ 53.30$ per week) ${ }^{(39)}$, which gives us confidence in our analysis methods. We acknowledge that spending was much greater than in a recent study using similar methods to estimate the dietary cost of foods as consumed by people participating in the NDNS, which reported a mean cost of 22.84 per day (equivalent to $£ 19.88$ per week) for those aged $40-49$ years $^{(9)}$. However, this discrepancy is likely to be due to the use of the DANTE food price database, based on 2004 food prices ${ }^{(9)}$, and not directly comparable with the current study which used 2013 prices. Food intake pre- and post-intervention was compared, providing valuable insight into how advice to improve overall dietary pattern affects the food purchasing patterns of individuals. Several limitations should also be acknowledged. Assumptions made in the costing of food products including package size, brand and availability at each of the supermarkets may not reflect the characteristics of the foods actually consumed by individuals as recorded in diet diaries. Food costs were calculated from $4 \mathrm{~d}$ food diaries recorded by participants recruited from multiple cohorts over a 2-year period and there may have been price, food supply and social 
changes (such as employment and wider economic measures) impacting on food purchase decisions by individuals recruited to the study. Participants were provided with some food pantry items to assist with compliance to the allocated dietary intervention and this may have affected other food purchasing decisions although both dietary interventions were provided with similar food items and quantities so any such influence should have affected both groups equally. Detailed data were not collected on other factors known to affect intake such as with whom and where food was eaten, level and confidence in cooking skills, availability of adequate storage facilities and kitchen equipment, as well as factors such as proximity to shops and car ownership. Such data would be important considerations for future studies, particularly in the analysis of cohort or survey diets.

\section{Conclusion}

The current study suggests that modifying habitual intake to achieve a cardioprotective diet, using the actual cost of foods as consumed, is not more expensive than baseline or conventional UK dietary food costs. The identification of specific food groups (specifically fish and snack foods) that may be a cost concern for people modifying their food intake is potentially useful for nutritionists and dietitians tailoring nutritional interventions for CVD prevention for individuals and populations. The use of theoretical models of dietary patterns and costs may not reflect the actual food choices made by individuals provided with advice to improve the quality of their existing diet. Further research focused on actual costs of adopting cardioprotective dietary advice by people with lower incomes, families and those from less advantaged backgrounds is warranted.

\section{Acknowledgements}

Acknowledgements: The authors thank the participants from the CRESSIDA study, and the CRESSIDA study investigators (Wendy Hall, Julia Darzi, Virginia Govoni, Sarah Berry, Zoe Maniou) for their support in conducting the CRESSIDA study, from which the dietary data for the present study were obtained. Financial support: This research received no specific grant from any funding agency in the public, commercial or not-for-profit sectors. The CRESSIDA study (from which the dietary data analysed in this research were obtained) was supported by funding from the UK Food Standards Agency, Department of Health and Public Health England. Several food companies also donated food products to the CRESSIDA study to aid compliance to the intervention. Funders and donor companies had no role in the design, analysis or writing of this article. Conflict of interest: D.P.R. reports no conflict of interest. L.M.G. is a recipient of research support in the form of two Diabetes UK project grants (grant numbers BDA 12/0004473 and BDA 14/0004967). T.A.B.S. is the scientific governor of the British Nutrition Foundation and honorary nutritional director of HEART UK. Authorship: All authors were involved in the design of the study including methods for data collection and data analysis. D.P.R. undertook all data collection, data analysis and wrote the manuscript. All authors commented critically on the manuscript and approved it for submission. Ethics of buman subject participation: This study was conducted according to the guidelines laid down in the Declaration of Helsinki and all procedures involving human subjects/patients were approved by the South London Research Ethics Committee (reference 10/H0802/24). Written informed consent was obtained from all participants.

\section{References}

1. Townsend MS, Aaron GJ, Monsivais P et al. (2009) Lessenergy-dense diets of low-income women in California are associated with higher energy-adjusted diet costs. Am J Clin Nutr 89, 1220-1226.

2. Aggarwal A, Monsivais P, Cook AJ et al. (2011) Does diet cost mediate the relation between socioeconomic position and diet quality? Eur J Clin Nutr 65, 1059-1066.

3. Bernstein AM, Bloom DE, Rosner BA et al. (2010) Relation of food cost to healthfulness of diet among US women. $\mathrm{AmJ}$ Clin Nutr 92, 1197-1203.

4. Andrieu E, Darmon N \& Drewnowski A (2006) Low-cost diets: more energy, fewer nutrients. Eur J Clin Nutr 60, 434-436.

5. Schröder H, Marrugat J \& Covas MI (2006) High monetary costs of dietary patterns associated with lower body mass index: a population-based study. Int J Obes (Lond) 30, 1574-1579.

6. Lopez CN, Martinez-Gonzalez MA, Sanchez-Villegas A et al. (2009) Costs of Mediterranean and western dietary patterns in a Spanish cohort and their relationship with prospective weight change. J Epidemiol Community Health 63, 920-927.

7. Carter SM \& Little M (2007) Justifying knowledge, justifying method, taking action: epistemologies, methodologies, and methods in qualitative research. Qual Health Res 17, 1316-1328.

8. Morris MA, Hulme C, Clarke GP et al. (2014) What is the cost of a healthy diet? Using diet data from the UK Women's Cohort Study. J Epidemiol Community Health 68, 1043-1049.

9. Timmins KA, Hulme C \& Cade JE (2015) The monetary value of diets consumed by British adults: an exploration into sociodemographic differences in individual-level diet costs. Public Health Nutr 18, 151-159.

10. Rao M, Afshin A, Singh G et al. (2013) Do healthier foods and diet patterns cost more than less healthy options? A systematic review and meta-analysis. BMJ Open 3, e004277.

11. Ottelin A-M, Lindström J, Peltonen M et al. (2007) Costs of a self-selected, health-promoting diet among the participants of the Finnish Diabetes Prevention Study. Diabetes Care 30, 1275-1277.

12. Cleary J, Casey S, Hofsteede C et al. (2012) Does a low glycaemic index (GI) diet cost more during pregnancy? Nutrients 4, 1759-1766.

13. Goulet J, Lamarche B \& Lemieux S (2008) A nutritional intervention promoting a Mediterranean food pattern does not afffect total daily dietary cost in North American women in free-living conditions. J Nutr 138, 54-59. 
14. Burney J \& Haughton B (2002) EFNEP: a nutrition education program that demonstrates cost-benefit. J Am Diet Assoc 102, 39-45.

15. Rydén P, Sydner YM \& Hagfors L (2008) Counting the cost of healthy eating: a Swedish comparison of Mediterranean-style and ordinary diets. Int J Consum Stud 32, 138-146.

16. Reidlinger DP, Darzi J, Hall WL et al. (2015) How effective are current dietary guidelines for cardiovascular disease prevention in healthy middle-aged and older men and women? A randomized controlled trial. Am J Clin Nutr 101, 922-930.

17. National Institute for Health and Clinical Excellence (2010) Cardiovascular Disease Prevention Public Health Guideline [PH25]. http://www.nice.org.uk/guidance/ph25 (accessed December 2016).

18. Sadler K, Nicholson S, Steer T et al. (2012) National Diet and Nutrition Survey - Assessment of Dietary Sodium in Adults (Aged 19 to 64 Years) in England, 2011. London: Food Standards Agency.

19. Food Standards Agency (2002) McCance and Widdowson's The Composition of Foods, Gth Summary Edition. Cambridge: Royal Society of Chemistry.

20. Campbell J, Foskett D \& Ceserani V (2008) Practical Cookery, 11th ed. London: Hodder Education

21. BBC Good Food (2014) BBC Good Food Recipes and Cooking Tips 2013. http://www.bbcgoodfood.com (accessed August 2014).

22. Raynor H (2002) A cost-analysis of adopting a healthful diet in a family-based obesity treatment program. $J$ Am Diet Assoc 102, 645-656.

23. Cade J, Upmeier H, Calvert C et al. (1999) Costs of a healthy diet: analysis from the UK Women's Cohort Study. Public Health Nutr 2, 505-512.

24. Darmon N, Briend A \& Drewnowski A (2004) Energy-dense diets are associated with lower diet costs: a community study of French adults. Public Health Nutr 7, 21-27.

25. Aggarwal A, Monsivais P \& Drewnowski A (2012) Nutrient intakes linked to better health outcomes are associated with higher diet costs in the US. PLoS One 7, e37533.

26. Drewnowski A \& Eichelsdoerfer P (2009) The Mediterranean diet: does it have to cost more? Public Health Nutr 12, $1621-1628$.

27. Department for Environment Food \& Rural Affairs (2013) Food Statistics Pocketbook 2012. London: DEFRA.
28. Carlson A \& Frazāo E (2012) Are Healthy Foods Really More Expensive? It Depends on How You Measure the Price, Economic Information Bulletin no. EIB-96. Washinngton, DC: US Department of Agriculture, Economic Research Service.

29. Monsivais P \& Drewnowski A (2009) Lower-energy-density diets are associated with higher monetary costs per kilocalorie and are consumed by women of higher socioeconomic status. J Am Diet Assoc 109, 814-822.

30. Ledikwe JH, Blanck HM, Khan LK et al. (2006) Lowenergy-density diets are associated with high diet quality in adults in the United States. J Am Diet Assoc 106, 1172-1180.

31. Darmon N, Darmon M, Maillot M et al. (2005) A nutrient density standard for vegetables and fruits: nutrients per calorie and nutrients per unit cost. J Am Diet Assoc 105, 1881-1887.

32. Haynes-Maslow L, Parsons SE, Wheeler SB et al. (2013) A qualitative study of perceived barriers to fruit and vegetable consumption among low-income populations, North Carolina, 2011. Prev Chronic Dis 10, E34.

33. Williams LK, Abbott G, Thornton L et al. (2014) Improving perceptions of healthy food affordability: results from a pilot intervention. Int J Behav Nutr Phys Act 11, 33.

34. Office for National Statistics (2013) Living Costs and Food Survey: Technical Report for Survey Year JanuaryDecember 2011. Great Britain and Northern Ireland. London: ONS

35. Drewnowski A, Monsivais P, Maillot M et al. (2007) Lowenergy-density diets are associated with higher diet quality and higher diet costs in French adults. J Am Diet Assoc 107, 1028-1032.

36. Kennedy LA, Hunt C \& Hodgson P (1998) Nutrition education program based on EFNEP for low-income women in the United Kingdom: 'Friends with Food'. J Nutr Educ 30, 89-99.

37. Pettigrew S, Moore S, Pratt IS et al. (2016) Evaluation outcomes of a long-running adult nutrition education programme. Public Health Nutr 19, 743-752.

38. Hardcastle SJ \& Blake N (2016) Influences underlying family food choices in mothers from an economically disadvantaged community. Eat Behav 20, 1-8.

39. Office for National Statistics (2013) Chapter 5: Weekly household expenditure, an analysis of the regions of England and the countries of the United Kingdom. In Family Spending 2012 [G Horsfield, editor]. London: ONS. 